\title{
EchoGéo
}

$14 \mid 2010$

Afrique, 50 ans d'indépendance : Dynamiques spatiales, identités, circulations

\section{Les riches heures et l'avenir incertain de la culture cotonnière en Afrique de l'Ouest et du Centre}

\section{Camille Renaudin}

\section{OpenEdition}

\section{Journals}

Édition électronique

URL : https://journals.openedition.org/echogeo/11955

DOI : 10.4000/echogeo.11955

ISSN : 1963-1197

Éditeur

Pôle de recherche pour l'organisation et la diffusion de l'information géographique (CNRS UMR 8586)

Référence électronique

Camille Renaudin, « Les riches heures et l'avenir incertain de la culture cotonnière en Afrique de l'Ouest et du Centre », EchoGéo [En ligne], 14 | 2010, mis en ligne le 13 décembre 2010, consulté le 31 juillet 2021. URL : http://journals.openedition.org/echogeo/11955; DOI : https://doi.org/10.4000/echogeo. 11955

Ce document a été généré automatiquement le 31 juillet 2021.

EchoGéo est mis à disposition selon les termes de la licence Creative Commons Attribution - Pas d'Utilisation Commerciale - Pas de Modification 4.0 International (CC BY-NC-ND) 


\title{
Les riches heures et l'avenir incertain de la culture cotonnière en Afrique de l'Ouest et du Centre
}

\author{
Camille Renaudin
}

\section{Introduction}

1 Au moment où René Dumont (1962) écrivait «l'Afrique noire est mal partie », il n'avait pas le recul nécessaire pour constater que l'histoire cotonnière contemporaine avait plutôt bien démarré. La culture cotonnière, héritée de la période coloniale, est en effet un des rares succès de développement agricole mené sur ce continent et les résultats des organismes cotonniers contrastent avec la marginalisation de l'Afrique subsaharienne dans les échanges internationaux. Au sein de ce continent, les pays cotonniers de la zone franc CFA se sont distingués des autres pays producteurs africains par l'augmentation remarquable de la production cotonnière au milieu du $\mathrm{XX}^{\mathrm{e}}$ siècle, qui a fait de cette zone le deuxième exportateur mondial de coton au début des années 2000 (Fok, 2010). Cette performance est le fruit d'investissements continus réalisés par les acteurs impliqués dans le secteur cotonnier (pouvoirs publics français au travers de la Compagnie Française de Développement des Fibres Textiles (CFDT), structures étatiques nationales et bailleurs de fonds notamment) au sein de filières qui ont été progressivement intégrées (Basset, 2002).

2 Aujourd'hui cependant, cette culture traverse une crise sans précédent qui ne semble pas, jusqu'à présent, trouver d'issue. Celle-ci tient, en partie, au fait que cette culture est demeurée, depuis la période coloniale, essentiellement exportée et donc totalement tributaire de facteurs exogènes (chute des cours mondiaux du coton, dépréciation du dollar américain, ...) sur lesquels les acteurs des filières n'ont aucune prise. Elle résulte également des difficultés des filières cotonnières francophones à opérer, dans un contexte de libéralisation et de privatisation des secteurs cotonniers en Afrique, les réformes adéquates pour demeurer compétitive sur le marché mondial. Cette crise est 
particulièrement grave, dans la mesure où elle engage le devenir de millions de personnes dont les revenus dépendent directement ou indirectement de cette production. Il est donc important aujourd'hui de comprendre les principaux défis que doivent relever les filières cotonnières africaines pour demeurer viables.

3 Pour cela, il importe de revenir sur certains des fondements des succès cotonniers dans les pays d'Afrique de l'Ouest et du Centre de la zone franc CFA, afin de mieux comprendre ensuite les raisons des bouleversements induits par la crise cotonnière. Il est également essentiel de montrer qu'au-delà des traits communs, les histoires cotonnières nationales ne se valent pas, et de mettre alors en lumière certains des facteurs endogènes qui gouvernent en partie les destinées cotonnières. Cela éclairera les enjeux des réformes à l'œuvre actuellement au sein de ces filières.

\section{Succès et impacts d'une culture héritée de l'histoire coloniale}

4 Diffusée dans les années 1920 en Afrique Occidentale Française (AOF) puis en Afrique Equatoriale Française $(\mathrm{AEF})^{1}$ pour répondre aux besoins d'une industrie textile française en plein essor, la culture industrielle du coton connut d'abord une période sombre. Imposée aux paysans qui devaient, par ce biais, s'acquitter de l'impôt, elle s'ajouta à la liste des symboles de la coercition coloniale qui sévissait à cette époque. Elle ne connut de succès qu'une fois "libre » et fut un événement majeur de l'évolution du monde rural dans les jeunes Etats africains.

\section{Des filières d'exportation héritées}

5 C'est au lendemain de la Seconde Guerre mondiale que la France engagea une véritable politique de développement de la culture cotonnière dans ses territoires africains. Elle fut menée sous l'égide de deux organismes cotonniers, l'un dédié à la recherche (Institut de recherche du coton et des textiles exotiques - IRCT) et l'autre à la production cotonnière (CFDT), qui surent tirer les leçons des échecs des tentatives de diffusion antérieures.

6 Le développement de la culture cotonnière se fit alors dans le cadre de filières qui furent progressivement intégrées. Elles eurent en charge, de l'amont à l'aval, du champ jusqu'à l'usine, toutes les étapes de la production cotonnière. La CFDT vulgarisait les résultats des recherches menées par l'IRTC (dans le domaine variétal, agronomique...) auprès des paysans et avait en charge la commercialisation et la transformation du coton-graine. Elle intervenait au départ dans les territoires africains aux côtés d'opérateurs privés puis obtint le monopole de la commercialisation et de l'égrenage du coton dans les zones de production. De culture obligatoire, la culture cotonnière devint libre pour les paysans et son achat garanti par la CFDT à un prix fixé en début de campagne agricole. Des systèmes de crédits gagés sur la production cotonnière furent mis en place, permettant aux producteurs d'accéder aux intrants nécessaires à la culture mais également de s'équiper en matériel agricole.

7 L'action conjuguée des deux organismes cotonniers et le soutien (notamment financier) que leur octroyèrent les pouvoirs publics français amorcèrent la progression spectaculaire de la production commerciale de coton, qui atteignait déjà 130000 tonnes 
au moment des indépendances dans cet ensemble géographique. Les indépendances acquises en 1960 ne furent pas de nature à remettre en cause le système intégré des filières africaines. La culture cotonnière apparaissait alors comme une des activités économiques (la principale dans certains pays) pouvant permettre aux jeunes Etats d'accéder aux devises dont ils avaient besoin pour financer leur développement. Ces derniers promurent donc cette culture et des sociétés cotonnières nationales virent le jour, dans lesquelles la CFDT obtint des participations au capital aux côtés des Etats. La France est restée ainsi le principal "partenaire » des filières cotonnières africaines, bien qu'elle ne fût pas seule à s'impliquer dans leur développement. Ses aides institutionnelles et financières ont en effet été complétées par des financements européens et par les ressources mises à disposition des Etats africains par le Fonds Monétaire International, la Banque Mondiale et la France au titre de l'Ajustement structurel (Alliot, 1999).

Développée initialement pour les besoins de l'industrie textile française, la production cotonnière est restée, dans ces pays, vouée à l'exportation. Quelques installations industrielles avaient pourtant vu le jour pendant la période coloniale. Cependant, les difficultés de fonctionnement étaient importantes, compte tenu des importations textiles en provenance de la métropole mais aussi de l'insuffisance de la main-d'œuvre, de son manque de qualification et surtout des coûts de transport et d'énergie qui grevaient la compétitivité de ces industries (Allix et al., 1956). Bien que des tentatives de valorisation de la fibre aient été menées jusque dans les années 1990, ces difficultés ne furent jamais surmontées. D'autant plus que les indépendances acquises, les Etats africains ont dû faire face aux importations de fripes en provenance des pays développés et à la concurrence des textiles asiatiques qui, avec la libéralisation progressive des échanges mondiaux, obéra toute possibilité d'un réel décollage industriel dans les pays francophones.

\section{Emergence des cotonniers africains sur le marché mondial du coton}

9 La réussite des filières cotonnières des pays de la zone franc CFA dans la deuxième moitié $\mathrm{du} \mathrm{XX}^{\mathrm{e}}$ siècle s'illustre par l'augmentation spectaculaire de la production cotonnière. Le bassin cotonnier ouest-africain auquel ces pays appartiennent, qui ne produisait que 13,5 \% du coton africain en 1970, représentait, en 2005, $58 \%$ de la production subsaharienne, faisant de cet ensemble la plus grande région productrice du continent. 
Illustration 1 - Production de coton fibre en 1970 et 2005 dans les bassins cotonniers africains

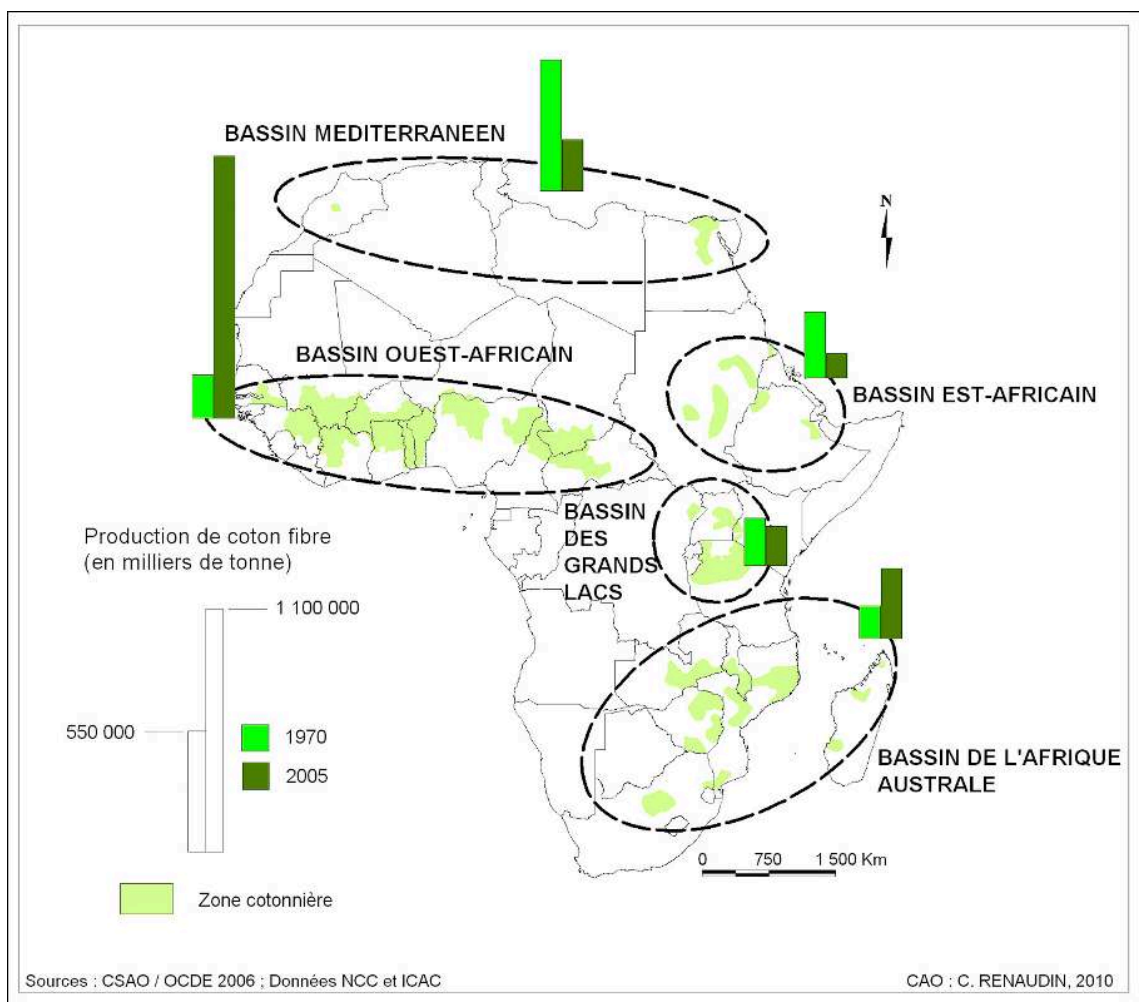

Sources : CSAO/OCDE, 2006 ; données NCC et ICAC. entre 1970 et 2005, a été essentiellement le fait des pays de la zone franc CFA, qui ont contribué à hauteur de 4,9\% par an à cet accroissement. Autrement dit, $93 \%$ de la production supplémentaire obtenue entre ces deux dates dans le bassin cotonnier ouest-africain a été réalisée dans les pays de la zone franc CFA. Ces résultats, qui sont le fait de l'amélioration de la productivité en termes de rendements et de l'accroissement des superficies cultivées en coton, ont permis à ces pays de multiplier par sept leur production entre 1970 et 2005. Leur part dans la production mondiale est alors passée de $1 \%$ à près de $4 \%$ entre ces deux dates, permettant aux zones cotonnières ouestafricaines de s'insérer dans le champ du coton mondial. Cette évolution est d'autant plus remarquable que la production y est pluviale et donc fortement soumise aux contraintes climatiques (illustration 2). Par ailleurs, elle est réalisée par de petites exploitations familiales qui cultivent en moyenne 1,5 ha de coton (Fok et al., 2004)2. 
Illustration 2 - Pays cotonniers d'Afrique de l'Ouest et du Centre de la zone franc CFA dans le champ du coton mondial

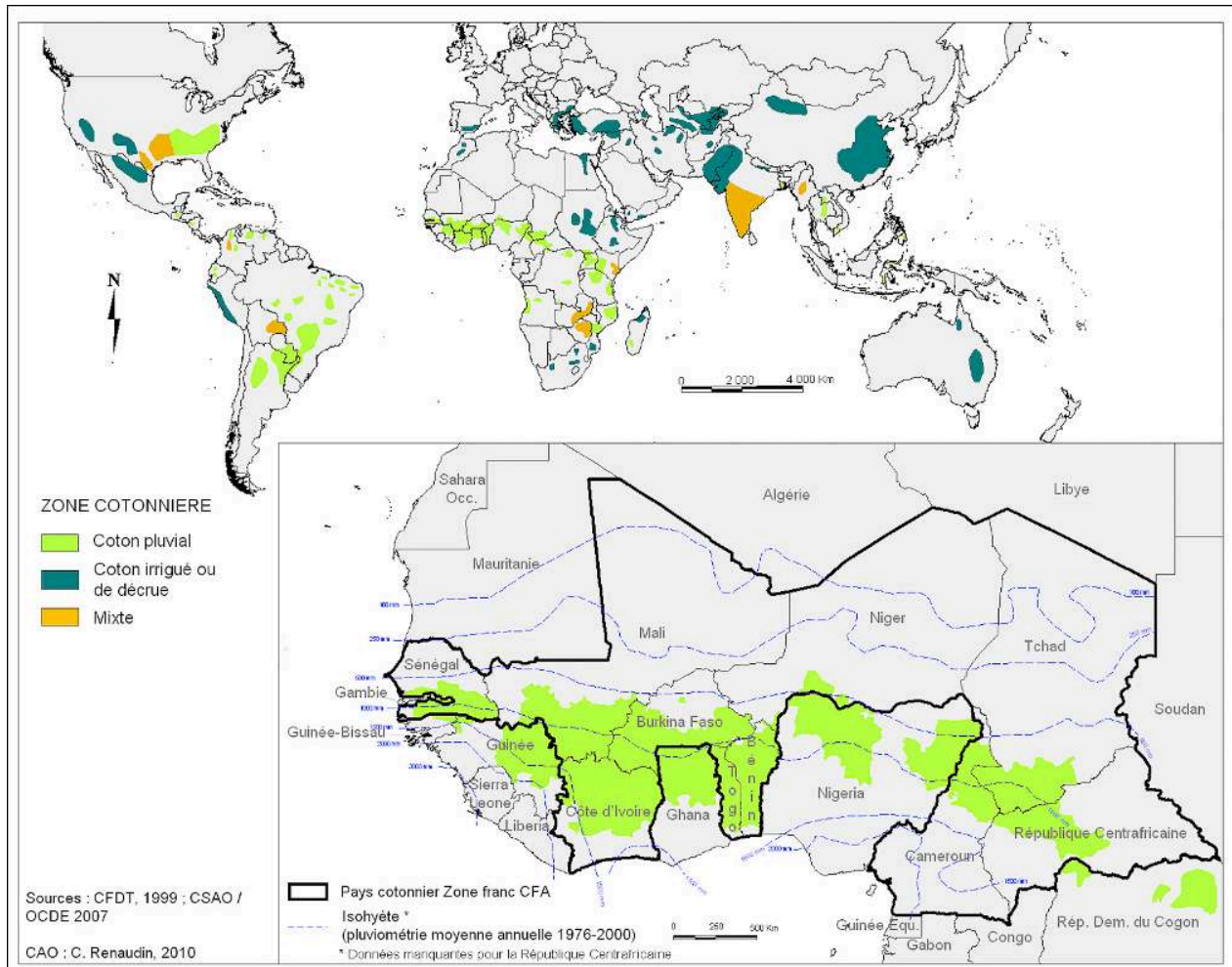

Sources : CFDT, 1999 ; CSAO/OCDE, 2007

De plus, à défaut d'une industrie textile à même de valoriser localement la fibre produite, ces pays sont devenus des exportateurs incontournables sur le marché mondial. Leurs exportations agrégées comptaient en 2005 pour plus de $10 \%$ des exportations mondiales, plaçant cet ensemble au deuxième rang, derrière les Etats-Unis et devant l'Ouzbékistan'. Il est cependant délicat de tenir l'Afrique de la zone franc CFA pour une entité homogène, puisque les pays qui la composent n'ont pas, jusqu'à présent, de stratégie d'exportation commune. En fait, chacun des pays cotonniers africains francophones s'engage seul sur le marché mondial. Leurs exportations se dirigent, pour l'essentiel, vers l'Asie du Sud et du Sud-Est, qui est aujourd'hui le pôle majeur de la consommation mondiale de fibre de coton.

\section{Des « success stories »}

Le succès de la production cotonnière dans cette partie du monde est celui d'une culture qui concerne deux à trois millions de ménages ruraux dans des campagnes où, historiquement - particulièrement dans la zone soudano-sahélienne -, il existe peu d'alternative de culture commerciale. Le coton procure ainsi directement ou indirectement des revenus à plus de 20 millions de personnes. Par ailleurs, et bien que la culture cotonnière ait été longtemps et vivement suspectée de concurrencer les cultures vivrières, elle a des effets d'entraînement certains sur l'agriculture de ces pays. Sa mise en place, dans le cadre de filières intégrées, a en effet favorisé la diffusion du progrès technique et de l'innovation dans les zones rurales, qui a profité à l'ensemble des cultures (Devèze et al., 2005). Les revenus monétaires tirés de la culture du coton et 
les systèmes de crédits qui ont permis aux producteurs d'investir dans des facteurs de production (charrue, animaux de trait) ont ainsi contribué à l'extension des superficies emblavées et à l'intensification des cultures, faisant des zones cotonnières de grandes zones productrices de céréales. De plus, à l'échelle des exploitations familiales - où la part du coton dans les systèmes de production ne représente qu'en moyenne $32 \%$ des superficies cultivées $^{4}$-, le système "coton-vivrier» a diminué la vulnérabilité alimentaire des ménages cotonniers; la rotation des cultures (coton-céréale) permettant l'augmentation des rendements des cultures semées après le coton, qui bénéficient des arrière-effets des engrais.

13 La diffusion de la culture cotonnière dans ces pays africains francophones a aussi permis la structuration et la "professionnalisation» des producteurs de coton. Ce processus a abouti à l'émergence de véritables organisations paysannes, dont les groupements de producteurs, à la base, assurent désormais l'approvisionnement en intrants et matériels agricoles, la gestion des crédits et la commercialisation primaire du coton-graine. Ces organisations professionnelles tendent à acquérir un rôle croissant dans la gestion des filières cotonnières, leur conférant ainsi la possibilité d'assumer leur rôle de syndicat de défense des producteurs.

En outre, en tant que sociétés nationales, les sociétés cotonnières ont été investies de missions de service public qui ont fait d'elles de « véritables sociétés de développement régional»(Hugon, 2005). En cela, elles ont pallié, en partie, l'insuffisance des financements des Etats en milieu rural. Ainsi, en construisant et surtout en entretenant des routes et des pistes rurales dans les zones cotonnières pour assurer l'approvisionnement en intrants et le transport du coton-graine, elles ont fortement contribué au désenclavement des zones rurales. De plus, le système d'un prix unique du coton-graine et des intrants dans les territoires nationaux a été également un facteur de cohésion sociale et territoriale, en permettant aux producteurs de produire, pourvu que les conditions agro-écologiques soient réunies, pour le même prix et ce, quelle que soit la distance entre leur village et les usines d'égrenage. L'uniformité du prix d'achat du coton et des intrants a ainsi contribué à stabiliser les producteurs et leur famille dans leur village (Ibid., 2005). De la même manière, les différents projets de développement et le système des "ristournes $"^{5}$, en permettant la mise en œuvre de projets d'utilité sociale et l'acquisition de biens à usage collectif, ont contribué à l'amélioration des conditions de vie en milieu rural.

L'ensemble des impacts de cette culture léguée par l'histoire en a fait une réussite de développement agricole. Cet héritage est cependant fragile. Les pays africains, en demeurant exportateurs nets, sont totalement dépendants des aléas d'un marché mondial sur lesquels ils n'ont aucune prise.

\section{Des crises sans fin}

16 Les filières cotonnières africaines sont en effet tributaires des cours mondiaux du coton. Or, ceux-ci, à l'instar des cours des prix des produits agricoles internationaux, se caractérisent depuis la fin des années 1970 par une tendance à la baisse. Par ailleurs, à cette dégradation des cours se conjugue une forte volatilité des prix liée à l'instabilité de l'offre et de la demande, aux fluctuations du change mais également aux subventions de grands pays exportateurs ou aux jeux spéculatifs des opérateurs sur les marchés, qui contribue à fragiliser les positions des pays africains. Chaque chute importante du prix 
du coton sur les cours mondiaux y provoque ainsi des crises de leurs filières qui accusent des déficits importants induits par la réduction des recettes d'exportation et parfois par l'augmentation des coûts.

\section{Les effets défavorables du contexte international sur les filières cotonnières africaines}

Depuis les années 2000, la crise cotonnière que traversent ces pays est particulièrement profonde. A l'instabilité du prix du coton s'est ajoutée l'augmentation du prix du pétrole, qui a conduit au renchérissement du coût des facteurs de production (intrants) et de ceux liés à l'aval de la production (énergie, transports, etc.). De plus, pour ces pays de la zone franc CFA, la dépréciation du dollar par rapport à l'euro depuis 2002 a aggravé la situation des filières cotonnières. Le graphique suivant montre nettement l'effet pénalisant de la dépréciation du dollar,alors même que le prix du coton a connu, parallèlement, une remontée de ses cours (figure 3). Ainsi, de 2002/2003 à 2007/2008, le prix mondial du coton fibre, exprimé en dollars, s'est accru de $25 \%$, tandis qu'en franc CFA, il a subi une diminution de près de $6 \%$.

Illustration 3 - Evolution des prix du coton selon l'indice A de Cotlook de 1993/1994 à 2007/2008

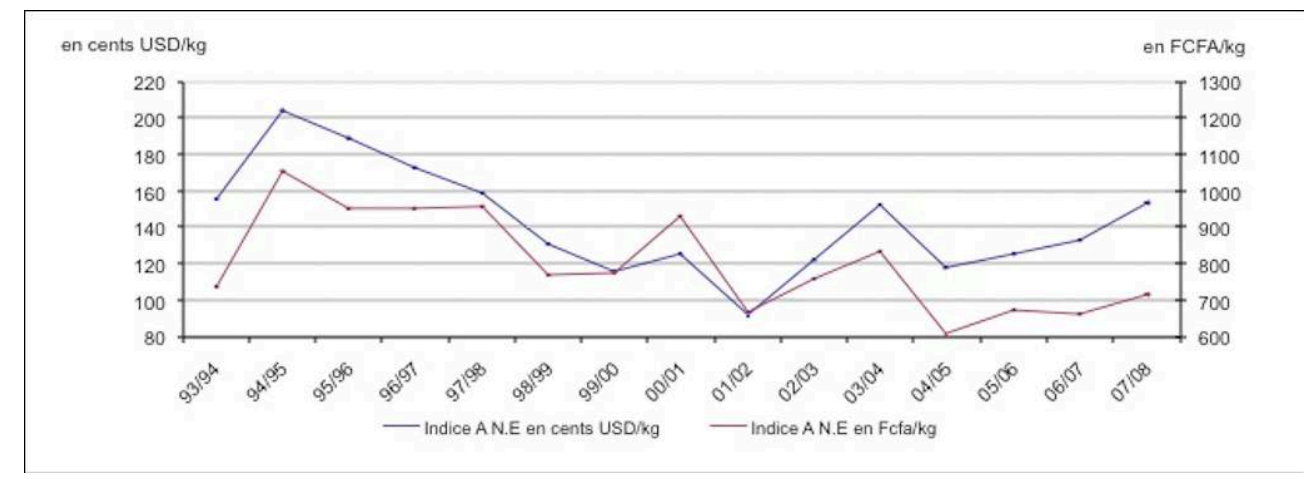

Source: données FARM.

Ces éléments ont provoqué des difficultés financières considérables au sein des filières, bien que les effets de la crise n'aient pas été visibles immédiatement. La remontée des cours du coton sur le marché international ainsi que les subventions publiques octroyées par les bailleurs de fonds et les Etats ont permis, en effet, de masquer un temps la dégradation des conditions de prix et les déficits accumulés par les sociétés cotonnières. Cependant, en 2005, les filières accusent le coup : la production cotonnière dans la zone franc CFA, qui avait connu une augmentation continue jusqu'à cette année, s'effondre brusquement. En 2008, seule la moitié des tonnages obtenus en 2005 est récoltée, la production ayant chuté de plus de $49 \%$ entres ces deux dates.

Cette chute de la production cotonnière, tout comme les déficits financiers des filières, sont préjudiciables non seulement pour la viabilité de la culture cotonnière, mais également pour la stabilité économique des pays d'Afrique francophone, compte tenu de l'importance des recettes d'exportation dans les économies nationales. Notamment au Burkina Faso, au Bénin, au Mali et au Tchad - où elles représentaient pour le premier, $56 \%$ de la valeur des exportations totales du pays et $30 \%$ pour les suivants dont les Etats sont dès lors dépendants des rentrées fiscales procurées par l'industrie 
du coton ${ }^{6}$. En outre, les difficultés financières des filières se répercutent sur les producteurs qui, en plus d'accuser une diminution sensible de leur revenu sous l'effet d'une baisse du prix d'achat du coton, subissent des retards de paiement importants et un risque accru d'endettement. Cette détérioration des conditions de production est à l'origine de la désaffection massive vis-à-vis de la culture cotonnière. Elle a une incidence certaine sur les conditions de vie des familles dont les revenus dépendent principalement de cette activité.

20 Ces impacts ont justifié l'émotion suscitée dès le début des années 2000 par de nombreuses analyses, qui ont imputé à la politique de subvention américaine aux producteurs de coton la déprime des cours (Pesche et al., 2006). Le jeu de la concurrence est en effet faussé sur le marché mondial du coton par les subventions accordées par des grands pays producteurs (Etats-Unis, mais également Union Européenne, Chine...) à leurs cotonculteurs et la question cotonnière, en ce sens, apparaît emblématique de l'hypocrisie des règles commerciales internationales. Quatre Etats africains (Bénin, Burkina Faso, Mali et Tchad), dans lesquels le secteur coton contribue à hauteur de 3 à $10 \%$ au Produit Intérieur Brut (PIB), ont engagé une « Initiative sectorielle en faveur du coton » à la cinquième conférence ministérielle de l'OMC à Cancún pour dénoncer cette situation et exiger la suppression totale des subventions et des mesures de soutien à la production. Elle s'est soldée par un échec lors des négociations menées au sein de l'OMC (Hazard et al., 2006).

21 Cette mobilisation des pays africains a eu l'effet pernicieux de laisser penser que la suppression des subventions permettrait à elle seule une sortie de crise. Or, il est aujourd'hui admis que leur suppression n'aurait qu'un effet (par ailleurs variable selon les études) de courte durée sur le prix mondial. En outre, ce combat - légitime - contre les subventions a occulté des facteurs endogènes qui peuvent être également responsables des difficultés de la production dans les pays cotonniers francophones. Ces facteurs tiennent aux environnements macro-économiques, politiques et géographiques inhérents à chacun de ces Etats. Aujourd'hui, au moment où les filières cotonnières doivent être plus que jamais compétitives, la stagnation des rendements du coton suscite de nombreuses inquiétudes quant à la viabilité des filières.

\section{Une stagnation inquiétante des rendements}

22 La stagnation, voire la baisse des rendements moyens de la culture cotonnière constatée dans les zones de production des pays d'Afrique de la zone franc CFA depuis les années 1990 est complexe à expliciter tant sont nombreux les facteurs qui interagissent pour expliquer cette évolution. Ils peuvent être, en effet, d'ordre structurel ou conjoncturel, relever des politiques institutionnelles, des environnements agro-climatiques, des pratiques culturales des agriculteurs, etc. Dès lors, la lecture de l'évolution des rendements moyens aux échelles de la zone franc CFA et des nations est très imparfaite. Elle est néanmoins source de préoccupations dans le contexte actuel de précarité financière des filières qui voit les crédits consacrés à la recherche et à la diffusion de l'innovation en milieu paysan se réduire (Vaissayre et al., 2006).

Alors que sur la période 1970-1990, les rendements moyens obtenus au champ ont progressé de 2,6 \% par an, ils ont ensuite connu une diminution de 0,9\% entre 1990 et $2008^{7}$ 
Illustration 4 - Evolution des rendements, des superficies et des productions de coton-graine dans les principaux pays producteurs de la zone franc CFA de 1990 à 2008

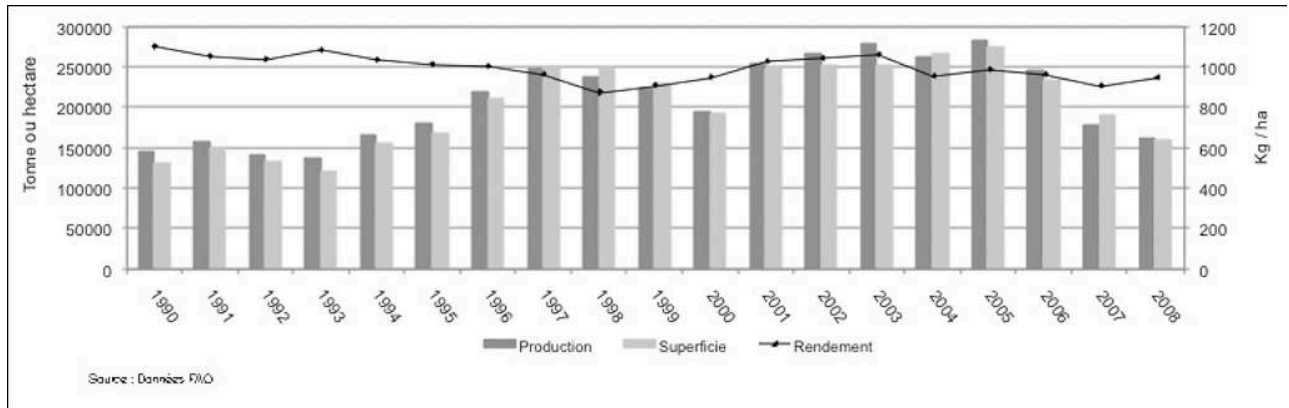

Les principaux producteurs de la zone Franc CFA sont le Benin, le Burkina Faso, le Cameroun, la République Centrafricaine, la Côte d'Ivoire, le Mali, le Sénégal, le Tchad et le Togo.

Source : données FAO

Autrement dit, la forte progression de la production enregistrée dans la zone franc CFA entre 1990 et 2005 - de plus de $10 \%$ - a été davantage le fait de l'extension des superficies cultivées que de l'augmentation de la productivité au champ. En Afrique centrale, le Cameroun a connu une croissance remarquable de sa production cotonnière, de 6,8 \% par an pendant cette période, alors que parallèlement les rendements n'ont augmenté que de $1 \%$ par an. Dans la partie occidentale de l'Afrique, où la production cotonnière des pays de la zone franc CFA a été multipliée par deux entre 1990 et 2005, seul le Sénégal a vu ses rendements progresser sensiblement - de 0,8 $\%$ par an. Les trois pays - Bénin, Mali, Burkina Faso -, dont les taux d'accroissement annuels moyens de production ont été supérieurs à $4,5 \%^{8}$, ont enregistré, respectivement, des taux d'accroissement annuels moyens des rendements de - 0,54 \%, - 2,15 \% et $0,04 \%$. Dès lors, les performances - différenciées - en matière d'augmentation de la production entre 1990 et 2005 sont à nuancer selon les pays.

Ces données, qui s'appuient sur des moyennes (de production, de rendement) masquent toutefois l'hétérogénéité des situations au sein des espaces nationaux. Il n'en demeure pas moins que l'extensification de la culture cotonnière est réelle et de plus en plus problématique dans ces pays où l'augmentation de la population reste continue dans les campagnes. Elle contribue en effet à l'augmentation de la demande en terres avec son corollaire, sa raréfaction et tend ainsi à exacerber les problèmes fonciers dans certaines zones rurales qui peuvent être à l'origine de mouvements migratoires importants et/ou se traduire par des conflits. En outre, la culture extensive est de nature à fragiliser les filières et les producteurs puisque, en s'exposant davantage aux aléas climatiques et aux ravageurs du cotonnier, elle est plus sujette à l'irrégularité de la production.

L'ensemble de ces phénomènes plaide dès lors, aujourd'hui, pour une augmentation des capacités des producteurs à intensifier durablement leur système de production dans la mesure où elle réduirait leur vulnérabilité et contribuerait à relancer la productivité agricole. Cette relance est d'autant plus nécessaire que les gains de productivité au champ obtenu dans les grands pays producteurs mondiaux pendant cette période (1990-2005) contrastent avec ceux des pays africains. La comparaison de l'évolution des rendements entre ces pays et ceux de la zone franc CFA est délicate, dans la mesure où les chiffres ne différencient pas les gains de rendement obtenus sous culture pluviale de ceux obtenus en irrigué. Cependant, elle permet d'entrevoir que l'écart se creuse 
entre ces pays. Ainsi, aux Etats-Unis, les rendements du coton-graine ont progressé en moyenne de 1,5\% par an entre 1990 et 2005, en Chine, de 2,3 \% par an et en Inde de 3,2 \%. Quant au Brésil, ils ont augmenté en moyenne de 7,3 \% par an.

Par ailleurs, les résultats des filières cotonnières ont été largement compromis par la crise des années 2000 ; l'un de ses effets les plus visibles ayant été la chute brutale de la production enregistrée à partir de 2005 dans les différents pays de la zone francs CFA (figure 5). Cette diminution n'a cependant pas eu la même ampleur selon les pays, démontrant des capacités de résistance à la crise plus ou moins importantes. Ainsi, entre 2005 et 2008, le Cameroun, le Tchad, le Togo et la Côte d'Ivoire ont accusé une baisse de leur production comprise entre 50 et $60 \%$. Au Mali, qui était le premier producteur de la zone franc CFA avant que le Burkina Faso ne lui ravisse la place en 2005 , la régression de la production a été particulièrement importante : - 64,4 \%. Au Bénin, la production cotonnière a diminué de $28,3 \%$, tandis qu'au Burkina Faso, elle n'a régressé que de $21,4 \%$.

Illustration 5 - Evolution de la production cotonnière entre 1990 et 2008 dans les pays de la zone franc CFA du bassin cotonnier ouest-africain

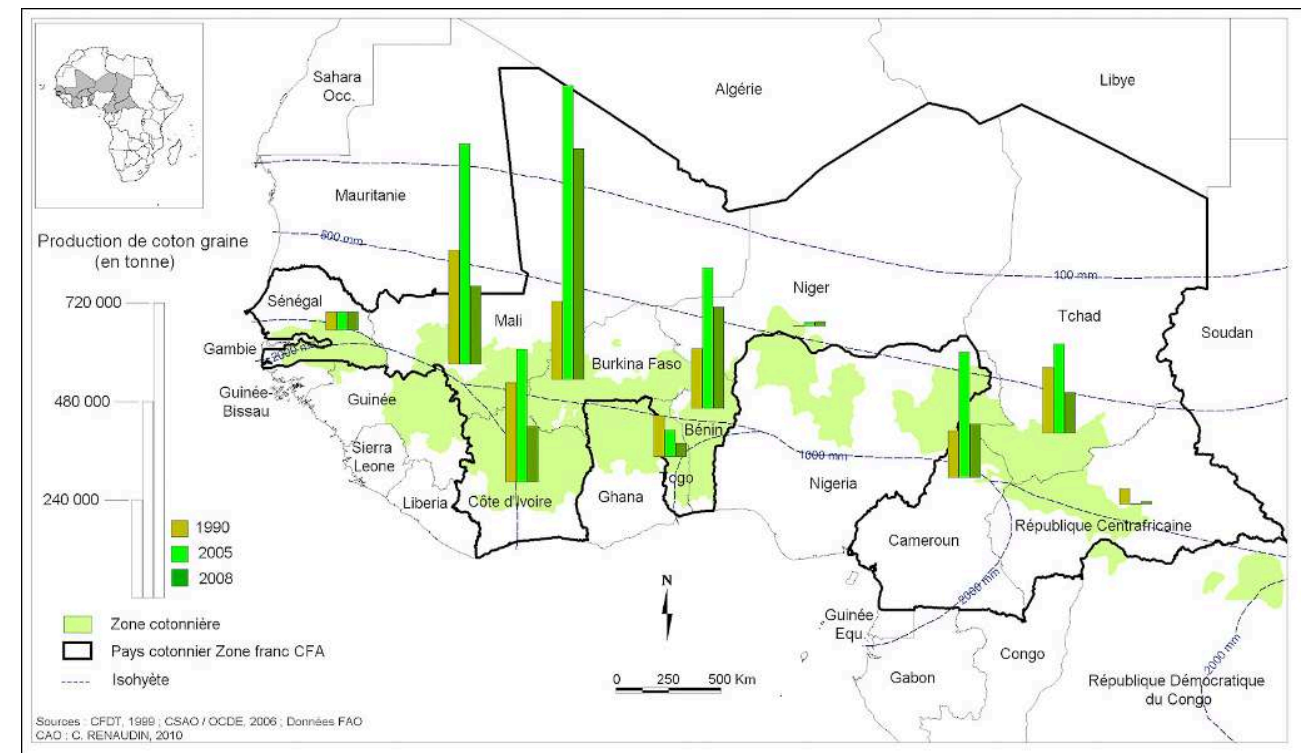

Sources : CFDT, 1999 ; CSAO/OCDE, 2006 ; données FAO.

Les disparités des trajectoires cotonnières dans les pays de la zone franc CFA entre 1990 et 2008 montrent, alors que toutes les filières sont confrontées au même contexte international, l'impérieuse nécessité pour ces pays de se concentrer sur les facteurs endogènes qui grèvent aujourd'hui leur compétitivité. Elles traduisent également la difficulté à opérer les réformes adéquates pour s'adapter à la fois aux contraintes de leur zone de production mais également pour s'ajuster au marché mondial du coton. Elles sont en effet engagées depuis les années 1990 dans des processus de libéralisation et de privatisation, dont la mise en œuvre engage leur avenir.

\section{Des ajustements des filières en période de crise}

Les institutions de Bretton Woods ont en effet préconisé dès les années 1980 des réformes de libéralisation et de privatisation des filières cotonnières. Le contexte s'y 
prêtait alors, puisque l'heure était à la mise en œuvre des politiques de stabilisation et d'ajustement structurel qui devaient transformer les économies administrées de rente des Etats africains - héritage des périodes coloniale et post-coloniale - en des économies de marché. La baisse des prix agricoles internationaux renforçait l'idée que les filières d'exportation - confrontées dans ce contexte à des difficultés financières - dépendaient d'un système « obsolète " au regard de l'évolution libérale de l'économie mondiale. Par ailleurs, la défense d'une plus juste rémunération des producteurs - que devait leur garantir le marché mondial - justifiait ces réformes.

\section{Des filières d'exportation ajustées} (es principaux acteurs de ces filières : sociétés cotonnières, CFDT, Etats, AFD, Coopération Française, Union européenne, FMI et Banque Mondiale. L'argumentaire du FMI et de la Banque mondiale reposait sur une vision strictement productive des activités cotonnières, avec un objectif en apparence consensuel, l'efficacité (Badiane et al., 2002). Pensée ainsi, cette efficacité ne prenait en compte ni les effets d'externalité du secteur ni les contraintes inhérentes aux pays africains (services publics défaillants, faiblesse du secteur privé...) qui, cumulées, ne réunissent pas, loin s'en faut, les conditions nécessaires pour une production rentable et compétitive dans laquelle s'investiraient des opérateurs privés. Par ailleurs, les évolutions institutionnelles et organisationnelles préconisées par les institutions de Bretton Woods ont suscité de nombreuses craintes d'une privatisation de services jugés "stratégiques" (recherche, conseil agricole, etc.) pour la viabilité de la culture cotonnière. Ces craintes ont été d'autant plus vives que de "stratégiques" pour les filières cotonnières, ces services deviennent "accessoires" aux yeux de la Banque Mondiale et du $\mathrm{FMI}^{9}$ (Badiane et al., 2002). conséquence de retarder la mise en place de ces réformes. Néanmoins, les filières cotonnières francophones se sont engagées dans les années 1990 vers la privatisation et la libéralisation des marchés liés au secteur coton (intrants, transport, crédit, l'égrenage, commercialisation, etc.). Ces réformes s'effectuent toutefois à des degrés et selon des modes d'organisation divers; aucune des filières n'est aujourd'hui libéralisée totalement. Elles sont par ailleurs parvenues partout à conserver les fondements du secteur coton (garantie d'achat du coton-graine et prix unique aux producteurs, uniformité et péréquation des prix des intrants, système d'octroi et de recouvrement des crédits d'intrants coton, etc.) qui avaient participé au succès de la culture cotonnière dans ces pays.

La pluralité des modes d'organisation des filières cotonnières aujourd'hui montre combien la prescription initiale d'un modèle unique de réformes, applicables à l'ensemble des filières, n'était pas réaliste. En fait, les réformes engagées ont été 
souvent le fruit de compromis négociés entre les principaux acteurs des filières. Leur mise en œuvre n'en a pas moins été émaillée de vives tensions dans la plupart des pays cotonniers, témoignant des difficultés à opérer des réformes structurelles douloureuses dans un contexte de crise qui demande des ajustements rapides.

\section{Diversité des évolutions institutionnelles} sans doute celles qui se rapprochent le plus du « modèle " promu par les institutions de Bretton Woods, qui préconise le démantèlement du monopole des sociétés cotonnières et la mise en concurrence des fonctions des filières (Hugon, 2005). C'est au Bénin que la libéralisation du secteur cotonnier a été la plus poussée. Elle a d'abord concerné la distribution des intrants puis le secteur de l'égrenage, qui s'est ouvert à des investisseurs privés dès 1992. Par ailleurs, l'entreprise nationale historique, la Société Nationale pour la Promotion Agricole (SONAPRA), a été progressivement privatisée et ses fonctions transférées à un organe interprofessionnel (l'Association Interprofessionnelle Cotonnière). Cette organisation nouvelle de la filière s'est cependant heurtée à de nombreux dysfonctionnements, qui ont abouti à une grave crise de confiance entre les acteurs (égreneurs et associations de producteurs); les dissensions se cristallisant notamment autour de la mise en place d'un nouveau mécanisme de recouvrement des crédits intrants (Fok, 2010). En Côte d'Ivoire également, le nouveau paysage cotonnier issu de la privatisation de la Compagnie Ivoirienne de Développement des Textiles (CIDT) en 1998, a été marqué par des tensions entre producteurs et égreneurs et entre les organisations paysannes. Celles-ci ont été attisées par le conflit ivoirien. Dans ce pays, la zone cotonnière a été scindée en trois aires géographiques, dans lesquelles chacun des opérateurs est en situation de monopole régional. Deux d'entre elles (la zone du Nord-Est et la zone du Nord-Ouest) ont été vendues à des repreneurs privés, tandis que la CIDT conserve la zone du Centre et demeure détenue par l'Etat ivoirien. Au Togo, la filière a entamé un processus de privatisation, en ouvrant l'égrenage à un opérateur privé dès 1995. Deux autres usines privées ont été ouvertes en 2000 et 2002, mais elles ont cessé de fonctionner à partir de 2007, laissant derrières elles d'importants impayés aux paysans (Fok, 2010).

Dans les autres pays d'Afrique de l'ouest, les réformes engagées se sont orientées plutôt vers le «modèle coopération française ", qui tend à conserver davantage l'intégration des filières (Hugon, 2005). Au sein des pays de la zone franc CFA, le Burkina Faso est le seul pays qui soit parvenu à mener un processus de libéralisation/privatisation de sa filière sans conflit majeur entre les acteurs. Dans ce pays, la privatisation de la société cotonnière nationale (SOFITEX) a été effectuée en 1999 par l'ouverture de son capital à l'Union Nationale des Producteurs de Coton (UNPC-B). L'année 2004 a ensuite marqué la fin du monopole de la SOFITEX, avec la cession de deux de ces zones d'intervention (qui représentaient alors $17 \%$ des capacités d'égrenage du pays) à des opérateurs en situation de monopole. La filière est gérée depuis 2006 par une Association 
Interprofessionnelle (AICB). Au Mali, en revanche, la privatisation de la société historique, la Compagnie Malienne de Développement des Textiles (CMDT), a été largement contestée, entraînant des reports successifs de sa mise en œuvre. Par ailleurs, un conflit a éclaté entre les paysans et la société cotonnière en 2000/2001, à la suite de la diminution du prix d'achat du coton aux producteurs et à des révélations de fraude et de corruption au sein de la CMDT. Les paysans ont alors « boycotté » le coton, provoquant une chute brutale de la production nationale. Depuis, la privatisation de la société cotonnière nationale a été plusieurs fois reportée, bien que l'option de monopoles locaux ait été retenue en 2003. Le Sénégal, quant à lui, a procédé à la privatisation de la SODEFITEX en cédant son capital à la CFDT (désormais Géocoton) et en ouvrant son capital aux producteurs.

En Afrique centrale, les processus de libéralisation/privatisation n'en sont qu'à leur début. Ils s'engageraient également vers le maintien des filières intégrées et vers une gestion interprofessionnelle des filières. Au Cameroun, bien que la privatisation de la société nationale, la SODECOTON, ait été décidée, aucun calendrier n'a encore été arrêté. Au Tchad, la privatisation de la COTONTCHAD n'a toujours pas abouti.

Les tensions qui ont émaillé la mise en œuvre des processus de privatisation et de libéralisation dans la plupart des pays cotonniers témoignent des réticences des acteurs à engager des réformes dans un contexte marqué par de grandes incertitudes liées, notamment, aux aléas du marché international. Ces incertitudes ont été par ailleurs accentuées par la privatisation, en 2008, du partenaire historique des filières francophones (la CFDT) au terme d'un processus engagé en 2005. Elles demeurent d'ailleurs encore aujourd'hui quant au rôle que jouera dans l'avenir cette nouvelle société (GEOCOTON) au sein des filières cotonnières francophones.

Le manque de recul interdit aujourd'hui de juger des impacts des changements institutionnels en cours dans les filières de la zone franc CFA bien que certaines études récentes (Tschirley et al., 2010; Banque Mondiale, 2008) se soient attachées à évaluer leur performance en fonction de leur mode d'organisation. Une des leçons cependant que l'on peut tirer des évolutions du paysage institutionnel cotonnier est l'émergence des organisations paysannes dans les organes décisionnels de ces filières. Cette émersion est « heureuse » à l'heure où la question du devenir de la culture cotonnière se pose. Ces OP, fédérées aux échelles nationales et regroupées depuis 2004 au sein de l'Association des Producteurs de Coton Africains (APROCA), sont en effet non seulement les plus à même aujourd'hui de défendre le maintien de cette culture qui procure des revenus à des millions de familles mais également de promouvoir des projets qui permettraient de relancer durablement la compétitivité des filières tout en tenant compte des contraintes et des intérêts des producteurs de coton.

\section{Conclusion}

La crise que traversent les pays cotonniers de la zone franc CFA montre la vulnérabilité de leur filière cotonnière face aux aléas du marché mondial. Les motifs d'inquiétude concernant l'avenir de la culture cotonnière sont d'autant plus nombreux que les effets du contexte international ont mobilisé les moyens pour remettre à flot des filières par ailleurs confrontées à des facteurs endogènes, comme la stagnation des rendements du coton, qui engagent tout autant leur viabilité. Ces facteurs relèvent à la fois des environnements politiques, institutionnels et des milieux agro-climatiques des zones 
cotonnières. Compte tenu, dès lors, de la diversité des situations dans la zone franc CFA il convient aujourd'hui que ces zones soient mieux caractérisées, tant à l'échelle sousrégionale qu'aux échelles nationales, puisque pour chacune d'entre elles les conditions d'une production cotonnière durable et productive, et donc le devenir de la culture, se posent de manière spécifique. Par ailleurs, cette caractérisation est indispensable dans la mesure où elle donnerait alors connaissance des modalités possibles pour initier des projets, adaptés aux systèmes de production et à l'environnement spécifique de chaque zone cotonnière. En ce sens, elle est une condition sine qua non pour répondre à l'impératif de durabilité et de compétitivité qui est celui des filières cotonnières francophones. Elle est également un préalable nécessaire à la mise en œuvre de politiques de diversification des cultures dont les filières ne peuvent faire l'économie pour réduire leur dépendance et celle des producteurs à cette seule culture qui demeurera tributaire du marché mondial.

\section{BIBLIOGRAPHIE}

Allix A., Gibert A., 1956. Géographie des textiles. Paris, Editions Génin, 564 p.

Badiane O., Ghura D., Goreux L. M., Masson P. R., 2002. Cotton Sector Strategies in West and Central Africa (French Version). World Bank Policy Research Working Paper No. 2867-B, 24 p. <http:// ssrn.com/abstract $=636230>$

Banque Mondiale, 2008. Organisation et performances des filières cotonnières africaines : leçon des réformes. Rapport final. Washington, DC, $188 \mathrm{p}$.

Basset T. J., 2002. Le coton des paysans. Une révolution agricole (Côte d'Ivoire 1880-1999). Paris, IRD Editions, $291 \mathrm{p}$.

Alliot J., 1999. Interventions de l'Agence française de développement en faveur des filières cotonnières, in CFDT, Cinquante ans d'action cotonnière au service du développement.Paris, CFDT (Hors Série), p. 83-87.

CNUCED, 2006. L'amélioration de la durabilité de la production du coton en Afrique de l'Ouest et du Centre. Nations Unies, $110 \mathrm{p}$

<http://www.unctad.org/en/docs/ditccom200512_enfr.pdf>

Devèze J.-C., Halley des Fontaines D., 2005. Le devenir des agricultures familiales des zones cotonnières africaines : une mutation à conduire avec tous les acteurs. A partir des casdu Bénin, du Burkina Faso, du Cameroun et du Mali. Paris, AFD EVA/STR,85 p.

Dumont R., 1962. L'Afrique noire est mal partie. Paris, Editions du Seuil, 287 p.

Estur G., 2008. Analyse comparative de l'organisation et des performances des filières cotonnières africaines. Qualité et commercialisation du coton fibre africain. World Bank, Africa Region Working Paper Series Number 121, 76 p. 
FAO, 2004. Coton : impact des mesures de soutien sur les pays en développement? Pourquoi les chiffres varient-ils? Dossiers de politique commerciale de la FAO concernant des questions liées aux négociations sur l'agriculture de l'OMC, $\mathrm{n}^{\circ} 1,4 \mathrm{p}$.

FARM, 2005. Le coton, quels enjeux pour l'Afrique ? Paris, FARM, 20 p.

Fok M, 2010. Facteurs d'efficacité des arrangements institutionnels en politique cotonnière africaine. Cah Agri, vol. 19, p. 68-74.

Fok A.C.M., 2006. Crises cotonnières en Afrique et problématique du soutien. Biotechnol. Agron. Soc. Environ., 10 (4), p. 311-323.

Fok M., Tazi S., 2004. Lessons learnt to overcome the costly and uncertain institutional re-arrangements under the globalization process : the African cotton case. Communication presented to Conference '85th EAAE Seminar', Florence, Italy, 14 p.

Fok M., Tazi S., 2003. Filières cotonnières en Afrique : restructuration, défaillances de coordination et règles collectives. Communication présentée au Séminaire S.H.S. du CIRAD, Montpellier, France, 24 p.

Hazard E. (dir.), 2006. Le livre blanc sur le coton. Négociations commerciales internationales et réduction de la pauvreté. Paris, Maisonneuve\&Larose, 197 p.

Hugon P., 2005. Les filières cotonnières africaines au regard des enjeux nationaux et internationaux. Paris, Ministère de l'Agriculture et de la Pêche, DPEI, Notes et Etudes Economiques n ${ }^{\circ} 23, \mathrm{p}$. 87-112.

Levrat R., 2008. Le coton en Afrique Occidentale et Centrale avant 1950. Un exemple de la politique coloniale de la France. Paris, L'Harmattan, 345 p.

Magrin G., 2001. Le sud du Tchad en mutation : des champs de coton aux sirènes de l'or noir. Montpellier, CIRAD, $470 \mathrm{p}$.

Mazoyer M., Roudart L. (dir.), 2005. La fracture agricole et alimentaire mondial. Nourrir l'humanité aujourd'hui et demain. Paris, Universalis, 193 p.

OCDE, 2006. Le coton en Afrique de l'Ouest. Un enjeu économique et social. Paris, Ed. OCDE, 131 p.

Pesche D., Nubukpo K., 2006. L'Afrique du coton à Cancun : retour sur la genèse d'une négociation, in Hazard E. (dir.), Le livre blanc du coton. Paris, Maisonneuve et Larose, p. 59-71.

Ton P., 2006. La durabilité de la production du coton en Afrique de l'Ouest et du Centre. CNUCED, p. 37-110.

Tschirley D. L., Poulton C., Gergely N., Labaste P., Baffes J., Boughton D, Estur G., 2010. Méthode d'analyse des effets différentiels des réformes sur les filières cotonnières africaines. Cah Agri, vol. $18, \mathrm{n}^{\circ} 5$, p. 68-74.

Vaissayre M., Ochou O. G., Herna S. A. O., Togola M., 2006. Quelles stratégies pour une gestion durable des ravageurs du cotonnier en Afrique subsaharienne? Cah Agri, vol. 15, nº, p. 80-84.

Zoundi J., Hussain K., Hitimana L., 2006. Libéralisation de la filière coton et innovation agricole en Afrique de l'Ouest. Cah Agri, vol. 15, n4, p. 17-21.

\section{NOTES}

1. En AOF, les premières tentatives de diffusion de la culture cotonnière ont été menées dès 1818 dans la vallée du Sénégal. Elles se révélèrent cependant infructueuses. Ces tentatives ont été 
renouvelées au début $\mathrm{du} \mathrm{XX}^{\mathrm{e}}$ siècle mais les résultats furent également décevants. Ce fut le lancement du programme Cadre en 1924 qui amorça ensuite le développement d'une politique cotonnière en AOF. La culture industrielle du coton ne fut cependant diffusée, à grande échelle, qu'au milieu du XX $X^{\mathrm{e}}$ siècle (Levrat, 2008).

2. Superficie moyenne dans les pays de la zone franc CFA (excepté le Niger) lors de la campagne 2001-2002 (Fok et al., 2004).

3. D'après les données du National Cotton Council of America (http://www.cotton.org/ ) et de l'International Cotton Advisory Committee (http://www.icac.org/).

4. Moyenne pour les pays de la zone franc CFA (excepté le Niger) lors de la campagne 2001-2002 (Fok et al., 2004).

5. Les sociétés cotonnières versent une commission sur achat aux Unions des producteurs, dont une part est redistribuée aux Groupements de Producteurs de Coton (GPC). Ces "ristournes » peuvent être attribuées alors à des projets d'utilité sociale: construction ou réparation de forages, d'écoles, de centres d'alphabétisation, de magasins, etc.

6. Depuis le milieu des années 2000 , le coton a cependant perdu beaucoup de poids dans le budget des Etats et dans le PIB de pays producteurs comme le Tchad, le Mali et le Burkina Faso en raison du développement d'activités extractives (pétrole au Tchad et or au Mali et au Burkina Faso).

7. Excepté le Niger.

8. Les taux d'accroissement annuels moyens de production se sont élevés, entre 1990 et 2005, à 5,8 \% au Bénin, à 4,5\% au Mali et à 9,2 \% au Burkina Faso.

9. Ils concernent notamment les services de vulgarisation, les activités de transport, l'achat et la distribution d'intrants et d'équipements ainsi que la commercialisation du coton-graine et des semences.

\section{RÉSUMÉS}

La culture du coton a été un des rares succès de développement agricole mené dans les pays d'Afrique de l'Ouest et du Centre de la zone franc CFA dans la deuxième moitié du XX $\mathrm{X}^{\mathrm{e}}$ siècle. La crise qu'elle traverse aujourd'hui engage pourtant son devenir et traduit la difficile insertion des filières cotonnières africaines sur le marché mondial. Elle met également en lumière le poids des contraintes inhérentes aux environnements des Etats africains. Autant de facteurs - exogènes et endogènes - que doivent prendre en compte les acteurs investis dans ces filières afin de s'orienter vers une amélioration durable de la production. L'enjeu est de maintenir des revenus à des millions de familles dans ces campagnes africaines.

Cotton farming has been one of the rare achievements in the agricultural development of Western and Central African CFA franc countries in the second half of the twentieth century. However, the economical crisis is now facing threats that jeopardize its future and shows the difficulty for African cotton industries to integrate the global market. It also reveals the inherent constrains to African countries environments. As much factors - exogenous and endogenous that the actors involved in these industries have to consider in order to promoting a long term improvement of their production. The stake is to maintain an income for millions of families in these African rural regions. 
INDEX

Mots-clés : Afrique zone franc CFA, coton, développement agricole, filière d'exportation, marché mondial

Keywords : African CFA franc, agricultural development, cotton, export industry, global market

\section{AUTEUR}

\section{CAMILLE RENAUDIN}

Camille Renaudin est doctorante à l'Université Paris IV - Sorbonne, UMR 8185 - Espaces, Nature et Culture et ATER à l'Université Paul Valery - Montpellier 3. Elle a publié : Renaudin C., 2010.

Vulnérabilité du paysannat cotonnier dans l'Est du Burkina Faso. Cahiers Agricultures, Vol. 19, n¹, p. 54-59. camille.renaudin@univ-montp3.fr 